\title{
Acute Ischemic Stroke in Sickle Cell Disease Challenges for Thrombolysis
}

\author{
Amal Al Hashmi Sanjith Aaron \\ Central Stroke Unit, Khoula Hospital, Ministry of Health of Oman, Muscat, Oman
}

\section{Keywords}

Blood · Hematology · Neurology · Sickle cell disease ·

Hemoglobinopathy · Acute ischemic stroke · Management · Thrombolysis · Tissue type plasminogen activator · Stroke mimics $\cdot$ Oman $\cdot$ Treatment $\cdot$ Vascular

\begin{abstract}
Sickle cell disease (SCD) is a hemoglobinopathy disorder that was recognized in 1949. Stroke is one of the most devastating complications of this disorder. The risk of stroke in SCD patients varies with the genotype; the highest rate has been reported with hemoglobin $\mathrm{S}$. Tissue type plasminogen activator (t PA) is class I recommended therapy for acute ischemic stroke (AIS) since 1996. Although it is unclear if SCD patients were included in the t PA trail, SCD has never been identified as contraindication. The debate of offering $t$ PA for adult SCD patient presenting with AIS continued for at least 2 decades. It is not up and until 2 years ago when the American Heart Association and American stroke association (AHA/ASA) announced that intravenous (IV) t PA can be offered to adult SCD patients presenting with AIS. Here, we report a case where successful IV thrombolytic therapy was offered to an adult SCD patient presenting with AIS with excellent outcome.

(c) 2020 The Author(s).

Published by S. Karger AG, Basel
\end{abstract}

karger@karger.com www.karger.com/dmj

Karger $\stackrel{\text { ' }}{5}$

GOPEN ACCESS
C 2020 The Author(s).

Published by S. Karger AG, Basel

This article is licensed under the Creative Commons AttributionNonCommercial-NoDerivatives 4.0 International License (CC BYNC-ND) (http://www.karger.com/Services/OpenAccessLicense). Usage and distribution for commercial purposes as well as any distribution of modified material requires written permission.

\section{Background}

In 1949, Pauling and his group described sickle cell disease (SCD) as a hemoglobinopathy [1]. Eight years later, the molecular misprint of SCD was identified as valine substituting the glutamic acid in the 6th position of the beta globin chain [2]. Although the relationship between SCD and stroke was known for more than a century, the treatment strategy especially in the setting of an acute ischemic stroke (AIS) was not clear. SCD can cause stroke through various mechanisms. Some are linked to the RBC morphology and others due to vascular endothelial injuries and coagulopathy.

The ridge shape of RBCs in sickled microcirculation hemoglobin can cause sludging and occlusion of blood vessels leading to ischemia in the cerebral [3]. Hypercoagulable state is due to increased thrombin and reduced antithrombotic protein $\mathrm{S}$ and $\mathrm{C}$ is another predisposing mechansim for stroke development in SCD [3]. SCD can also lead to flow-related hemodynamic injury to the endothelial cells, which promote adherence of sickle cells to the endothelium and lead to stroke. The hemoglobin S ( $\mathrm{Hb} \mathrm{S}$ ) damage specific sites of the endothelial cells and lead to the cytokines, adhesion molecules, and tumor necrosisfactor release and hence stroke development. In addition SCD patients are also prone to the development of secondary moyamoya disease. Furthermore around 20-

Amal Al Hashmi

Senior Consultant Neurologist, Head Central Stroke Unit, Neurology Department Khoula Hospital, Ministry of Health of Oman, PO Box 90, 116 Mina Al Fahal PC 116 Muscat (Oman) amal.m.alhashmi@gmail.com 

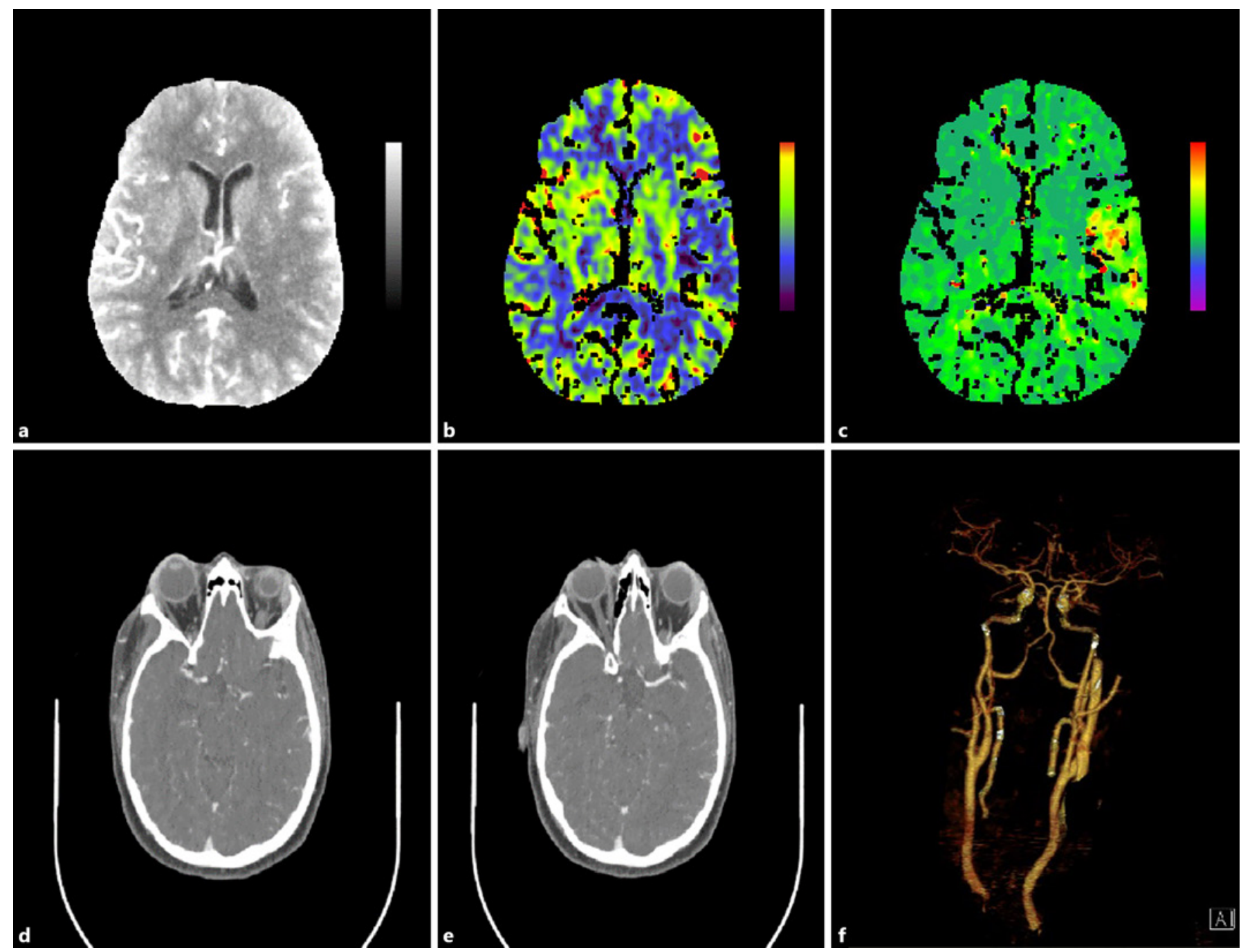

Fig. 1. Baseline imaging. Normal CT perfusion (a) CBV map (b) and TTP maps (c) showing perfusion deficit and a small matched defect in left insula. d, e CT angiogram showing occlusion of the superior division of left MCA beyond the bifurcation. $\mathbf{f}$ CT angiogram with reconstruction. CBV, cerebral blood volume; TTP, time to peak.

$30 \%$ of patients with SCD have positive cerebral angiogram; this predisposes to both ischemic and intracranial hemorrhage strokes [4] and finally, SCD HLA-related susceptibilities for stroke [5].

In 1998, Adams and his group reported that exchange transfusion and frequent transfusion has shown to substantially reduce the risk of a first stroke [6]. Yet, the treatment with thrombolysis therapy in the acute setting of stroke and SCD remained controversial till the lasted update of acute stroke guideline released by AHA/ASH in 2018 [7].

\section{Case Report}

A 35-year-old fully independent Omani female who was a known case of SCD presented to our emergency room within the window for thrombolysis with an evolving L MCA stroke; she was having right hemiparesis and worsening aphasia. She had earlier complications of SCD in the form of a vascular necrosis of femoral heads in 2016 which needed bilateral hip replacement. She had a history of multiple vascular occlusive crisis requiring admissions. She was very irregular on follow-up with her hematologist. She was only on folic acid with a baseline $\mathrm{Hb} 8-9$ 


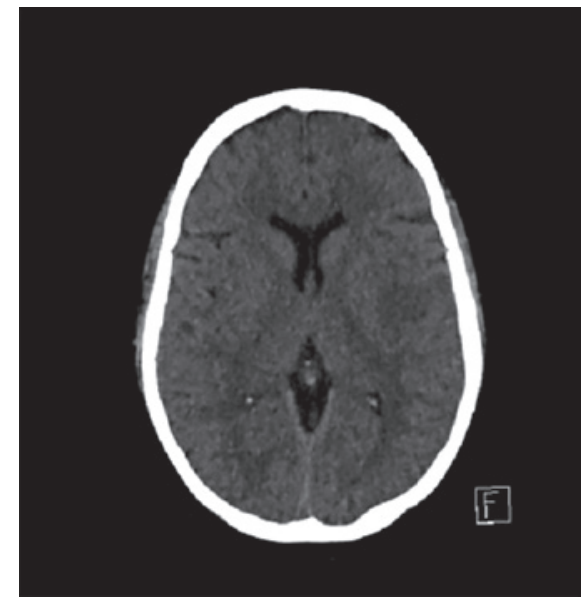

Fig. 2. Follow-up imaging. Plain CT head showing clear small hypodensity in left insula without hemorrhagic transformation.

$\mathrm{g} / \mathrm{dL}$. At the time of presentation, her vital signs were as follows: BP 155/80 $\mathrm{mmhg}$, pulse: $86 / \mathrm{min}$ regular, and temperature: $37.2^{\circ} \mathrm{C}$. Her blood sugar was: $5.9 \mathrm{mmol} / \mathrm{L}$ and her National Institute of Health Stroke Scale (NIHSS) score was 6 . She was conscious, alert, oriented but globally aphasic with bilaterally reactive and equal pupils. She had a normal visual field with full extra ocular motor movements. However, she had right-sided upper motor neuron facial palsy and right-sided pronation drift but normal tone with $-4 / 5$ power for both upper and lower limbs on the right, otherwise the power was $5 / 5$ elsewhere. Her reflexes were brisk but symmetrical with upgoing toe on the right side. Her sensory and cerebellar examinations were both normal.

The CT and CT angiogram showed an evolving infarct in left MCA territory caused by occlusion of the superior division of left MCA beyond the bifurcation (Fig. 1d-f). The CT Perfusion showed a small matched defect in the left insula with a small penumbra (Fig. 1a-b). She was treated immediately with intravenous (IV) thrombolysis with tissue type plasminogen activator ( $\mathrm{tPA}$ ) within $35 \mathrm{~min}$ of arrival (as per the latest recommendations and guidelines for acute stroke in a case of SCD disease). Her laboratory testing showed a platelet count of $400,000 / \mathrm{mcl}$, INR of 1.0 , and hemoglobin $8.70 \mathrm{~g} / \mathrm{dL}$. Her total bilirubin level was 22.58 $\mathrm{mg} / \mathrm{dL}$, ALT:16.6 $\mu / \mathrm{L}$, ALP: $45 \mu / \mathrm{L}$, urea $2 \mathrm{mmol} / \mathrm{L}$, and creatine: $55.58 \mathrm{mmol} / \mathrm{L}$. ECG did not show any arrhythmia. Subsequently, her hemoglobin electrophoresis testing revealed $\mathrm{Hb} \mathrm{A}: 4.30, \mathrm{Hb} \mathrm{A} 2: 5.70, \mathrm{Hb} F: 0.20, \mathrm{Hb} \mathrm{S}: 89.80$, and other variants: 0.00 . Given her high $\mathrm{Hb}$ S level (89\%), she required urgent exchange transfusion.

Acute Ischemic Stroke in Sickle Cell

Disease Challenges for Thrombolysis
Transfer to hematology department at other hospital was arranged. Prior to the transfer, her clinical examination showed mild improvement in her right-sided limb power; $4^{+} / 5$. Additionally, her aphasia has improved slightly, she was able to comprehend fully but has some amount of expressive aphasia, and her NIHSS has reduced form around 6 to 4 . A repeat CT head ( $8 \mathrm{~h}$ after $\mathrm{t}$ PA) showed acute infarct involving left insular cortex (Fig. 2), with no evidence of hemorrhagic transformation. There were old infarcts in right frontal cortex and left cerebellar hemisphere. She received an exchanged transfusion on the next day and her $\mathrm{Hb} S$ level dropped to $32.5 \%$ and her $\mathrm{Hb}$ raised to $10 \mathrm{~g} / \mathrm{dL}$. She was started on hydroxyurea $500 \mathrm{mg}$. Physiotherapy and speech therapy were initiated. Her carotid Doppler and echo cardiogram were normal. Her repeated CT $24 \mathrm{~h}$ following thrombolysis therapy reveled similar findings seen on the second CT head with no hemorrhagic transformation and absence of any new findings. She was then discharged on anti-platelet for secondary prevention. Three months later, she was seen at the stroke clinic. During this visit, she reported significant improvement of her symptoms and denied any new symptoms. Her NIHSS had improved further to a score of 1 with only expressive aphasia for low frequency words.

\section{Discussion}

SCD patients are at a higher risk of developing stroke compared to general population, with a prevalence of $3.5 \%$ [5]. Adults with SCD are also at risk of recurrent stroke with two third having recurrent stroke within 2 years of their initial stroke [8]. Although SCD patients can suffer from both stroke subtypes, ischemic and intracranial hemorrhage, risk factors differ for each stroke sub types $[3,8]$. Ischemic strokes are associated with prior transient ischemic attack, increased systolic blood pressure, acute coronary syndrome, and nocturnal hypoxemia [9]. While intracranial hemorrhage in SCD patients is associated with older age, treatments with corticosteroids or non-steroidal anti-inflammatory drugs and blood transfusion within 2 weeks $[3,9]$ were started.

Stroke symptoms and signs in SCD patients are similar to those in other stroke patients; therefore, excluding other traditional risk factors is mandatory. Treating SCD patients presenting with AIS symptoms with thrombolytic therapy has been always a concern as these patients can have advanced vasculopathy and secondary moya- 
moya disease which can increase their risk of developing intracranial hemorrhage when treated with thrombolysis therapy. Moreover, other pathologies can cause focal neurological deficits in a patient with SCD mimicking strokes, some of which can be contraindications for offering IV thrombolytic therapy. Hemiplegic migraine mimicking acute strokes are common especially in the younger populations with SCD [10]. Todd's palsy in patients with SCD with the prevalence of seizures, especially in the younger age-groups, is extremely highly compared with the general population. In addition, patients presenting with post-ictal weakness can be mistaken as a case of stroke [11]. Cerebral venous thrombosis can occur in SCD patients, and sometimes an acute CVST can mimic strokes [12]. Rarely reversible posterior leukoencephalopathy syndrome can be a complication of SCD, especially in children with associated severe acute chest syndrome [13]. It is also important to remember that patient with SCD can have silent cerebral infarcts [14]. Therefore, in the setting of a focal neurological deficit, it is important not to miss a second complication like aneurysms with or without subarachnoid hemorrhage while deciding on acute or secondary preventive strategies $[15,16]$.

The treatment with thrombolysis therapy in the acute setting of stroke and SCD remained controversial till the last update of acute stroke guideline released by AHA/ ASH in 2018 [7]. Case-control analysis was performed using the population from the AHA GWTG-Stroke registry. This analysis included 832 adult cases with SCD and 3,328 age-, sex-, and race-matched controls without SCD with similar severity of neurological deficits at presentation. It found out that SCD did not have a significant impact on the safety or the outcome at discharge of treatment with IV t PA [17].

Although this analysis supports treating SCD patients with thrombolysis therapy, the increased risk of hemorrhagic transformation should be clearly explained to the patients and their families. Moreover, looking for any underlying causes of hemorrhage, such as aneurysms, hypertension, and coagulopathies is mandatory. In Oman, the frequency of SCD was reported as high as $3.8 \%$ in a study of 5,000 subjects from 3 states of Arabian peninsula [18]. In 2001, Al Riyami et al. [19] and his group reported the overall prevalence of $\mathrm{Hb} \mathrm{S}$ in Oman is 5.8 percent with significant regional variations. It is essential to recognize this group of SCD patients and treat them with thrombolysis when presenting with AIS and in the absence of any contraindications. In addition to the treatment with thrombolysis and thrombectomy in the setting of acute stroke, SCD patients will require exchange transfusion to lower the $\mathrm{Hb}$ SS to $<30 \%$ [9].

Hulbert et al. [20] and his group showed that exchanged transfusion at acute presentation is associated with lower stroke recurrence compared with simple transfusion. The decision of IV thrombolysis was clear in our case due to the absence of absolute contraindication. Our patient was initially treated with thrombolysis, but not thrombectomy, as her cerebral CT angiography did not reveal any large vessel occlusions. She also underwent exchange transfusion the next day. This is the first case from Oman where successful IV thrombolysis was performed in a known SCD patient presenting with AIS.

\section{Conclusion}

Multiple and complex pathophysiological mechanisms can cause stroke in SCD. Treating acute stroke in SCD patients with thrombolysis seem to be beneficial and safe. A careful history, clinical examination, and reviewing the imaging features will help take a judicious decision before offering thrombolysis.

\section{Statment of Ethics}

Our patient gave a written informed consent to publish this case report (including the publications of the images).

\section{Conflict of Interest Statement}

The authors have no conflicts of interest to declare.

\section{Funding Sources}

The authors did not receive any funding.

\section{Author Contributions}

A.H. Managed the case, performed the literature search, and contributed to the writing of the case report. S.A. helped in the literature search and contributed to writing of the case report. 


\section{References}

1 Pauling L, Itano HA, Singer SJ, Wells IC. Sickle cell anemia a molecular disease. Science. 1949;110(2865):543-8.

2 Ingram VM. Gene mutation in human hemoglobin: the chemical difference between normal and sickle cell hemoglobin. Nature. 1957; 180:326-9.

3 Switzer JA, Hess DC, Nichols FT, Adams RJ. Pathophysiology and treatment of stroke in sickle-cell disease: present and future. Lancet Neurol. 2006;5(6):501-12.

4 Arias EJ, Derdeyn CP, Dacey RG Jr, Zipfel GJ. Advances and surgical considerations in the treatment of moyamoya disease. Neurosurgery. 2014;741(Suppl 1):S116-25.

5 Hoppe C, Klitz W, Noble J, Vigil L, Vichinsky E, Styles L. Distinct HLA associations by stroke subtype in children with sickle cell anemia. Blood. 2003;101(7):2865-9.

6 Adams RJ, McKie VC, Hsu L, Files B, Vichinsky E, Pegelow C, et al. Prevention of a first stroke by transfusions in children with sickle cell anemia and abnormal results on transcranial Doppler ultrasonography. N Engl J Med. 1998;339(1):5-11.

7 Powers WJ, Rabinstein AA, Ackerson T, Adeoye OM, Bambakidis NC, et al. Guidelines for the early management of patients with acute ischemic stroke: a Guideline for Healthcare Professionals From the American Heart Association/American Stroke Association. 2018.
8 Ohene-Frempong K, Weiner SJ, Sleeper LA, Miller ST, Embury S, Moohr JW, et al. Cerebrovascular accidents in sickle cell disease: rates and risk factors. Blood. 1998;91(1):28894.

9 Strouse JJ, Lanzkron S, Urrutia V. The epidemiology, evaluation and treatment of stroke in adults with sickle cell disease. Expert Rey Hematol. 2011;4(6):597-606.

10 Niebanck AE, Pollock AN, Smith-Whitley K, Raffini LJ, Zimmerman RA, Ohene-Frempong $\mathrm{K}$, et al. Headache in children with sickle cell disease: prevalence and associated factors. J Pediatr. 2007;151(1):67-e1.

11 Prengler M, Pavlakis SG, Boyd S, Connelly A, Calamante F, Chong WK, et al. Sickle cell disease: ischemia and seizures. Ann Neurol. 2005;58(2):290-302.

12 Van Mierlo TD, van den Berg HM, Nievelstein RA, Braun KP. An unconscious girl with sickle-cell disease. Lancet. 2003;361(9352): 136.

13 Henderson JN, Noetzel MJ, McKinstry RC, White DA, Armstrong M, DeBaun MR. Reversible posterior leukoencephalopathy syndrome and silent cerebral infarcts are associated with severe acute chest syndrome in children with sickle cell disease. Blood. 2003; 101(2):415-9.

14 Hulbert ML, McKinstry RC, Lacey JL, Moran CJ, Panepinto JA, Thompson AA, et al. Silent cerebral infarcts occur despite regular blood transfusion therapy after first strokes in children with sickle cell disease. Blood. 2011; 117(3):772-9.
15 Anson JA, Koshy M, Ferguson L, Crowell RM. Subarachnoid hemorrhage in sickle-cell disease. J Neurosurg. 1991;75(4):552-8.

16 Oyesiku NM, Barrow DL, Eckman JR, Tindall SC, Colohan AR. Intracranial aneurysms in sickle-cell anemia: clinical features and pathogenesis. J Neurosurg. 1991;75(3):35663.

17 Webb J, Kwiatkowski JL. Stroke in patients with sickle cell disease. Expert Rev Hematol. 2013;6(3):301-16.

18 White JM, Byrne M, Richards R, Buchanan T, Katsoulis E, Weerasingh K. Red cell genetic abnormalities in Peninsular Arabs: sickle haemoglobin, G6PD deficiency, and alpha and beta thalassaemia. J Med Genet. 1986;23(3): 245-51.

19 Al-Riyami AA, Suleiman AJ, Afifi M, AlLamki ZM, Daar S. A community-based study of common hereditary blood disorders in Oman. East Mediterr Health J. 2001;7(6): 1004-11.

20 Hulbert ML, Scothorn DJ, Panepinto JA Scott JP, Buchanan GR, Sarnaik S, et al. Exchange blood transfusion compared with simple transfusion for first overt stroke is associated with a lower risk of subsequent stroke: a retrospective cohort study of 137 children with sickle cell anemia. J Pediatr. 2006;149(5):710-2. 